\title{
The meaning of self-reported death anxiety in advanced cancer
}

\author{
Eryn Tong, Amy Deckert, Nina Gani, Rinat Nissim, Anne Rydall, \\ Sarah Hales, Gary Rodin, and Chris Lo
}

Version Post-print/accepted manuscript

Citation Tong E, Deckert A, Gani N, Nissim R, Rydall A, Hales S, Rodin G, Lo (published version) C. The meaning of self-reported death anxiety in advanced cancer.

Palliative Medicine. 2016 Sep; 30(8):772-779. doi:

$10.1177 / 0269216316628780$

Copyright information Copyright (C) 2016 SAGE Publications. Reprinted by permission of SAGE Publications.

How to cite TSpace items

\begin{abstract}
Always cite the published version, so the author(s) will receive recognition through services that track citation counts, e.g. Scopus. If you need to cite the page number of the author manuscript from TSpace because you cannot access the published version, then cite the TSpace version in addition to the published version using the permanent URI (handle) found on the record page.
\end{abstract}

This article was made openly accessible by $U$ of $T$ Faculty. Please tell us how this access benefits you. Your story matters. 
Full citation and link to final published version:

Tong E, Deckert A, Gani N, Nissim R, Rydall A, Hales S, Rodin G, Lo C. The meaning of self-reported death anxiety in advanced cancer. Palliative Medicine. 2016 Sep;

30(8):772-779. doi: 10.1177/0269216316628780 [Epub 2016 Feb 8] 


\section{The meaning of self-reported death anxiety in advanced cancer}

Eryn Tong ${ }^{1}$, Amy Deckert ${ }^{1}$, Nina Gani ${ }^{2}$, Rinat Nissim ${ }^{1,3}$, Anne Rydall ${ }^{1}$, Sarah Hales ${ }^{1,3}$, Gary Rodin $^{1,3}$, Chris Lo ${ }^{1,3}$

1 Department of Supportive Care, Princess Margaret Cancer Centre, University Health Network, Toronto, Ontario, Canada

2 Department of Psychosomatic Medicine and Psychotherapy, University Hospital Tuebingen, Germany

3 Department of Psychiatry, University of Toronto, Toronto, Ontario, Canada

Corresponding author:

Dr. Chris Lo

Princess Margaret Cancer Centre

Department of Supportive Care, Research Division

LuCliff Place, $23^{\text {rd }}$ Floor, Suite 2303

700 Bay St., Toronto, Ontario, M5G 1Z6, Canada

Email: chrislo@uhnresearch.ca 


\begin{abstract}
Background: Death anxiety is important but understudied in palliative care. New selfreport measurements have been developed, but their interpretation and clinical utility may not be evident.

Aim: To inform our understanding of death anxiety in patients with advanced cancer by exploring the relationship between this self-reported symptom and its clinical presentation.

Design: Participants were part of a psychotherapy trial in advanced cancer. First therapy session transcripts were analyzed using interpretive description in patients reporting low, moderate and high death anxiety on the Death and Dying Distress Scale (DADDS).

Setting/participants: 16 participants (10 women and 6 men) with advanced or metastatic cancer were recruited at The Princess Margaret Cancer Centre, Toronto, Canada. In this sample, 6 reported low death anxiety scores (DADDS 0-19), 5 moderate (DADDS 20-50), and 5 high (DADDS 51-75).

Results: The low death anxiety group exhibited psychological readiness for death, or contrastingly, non-reflectiveness about death. The moderate group recognized the imminence of mortality, which impacted treatment decisions and future plans. Prior experience with death was discussed as raising the salience of mortality. The high group felt dominated by powerful emotions and could not make sense of their situation. Their distress was exacerbated by substantial relational concerns.

Conclusions: Self-reported death anxiety is affected by the awareness and ability to reflect on mortality. DADDS scores may facilitate exploration of this symptom as part of a clinical assessment and may serve to guide treatment approaches. Greater attention to death anxiety is consistent with and recommended by contemporary approaches to palliative care.
\end{abstract}

\title{
Keywords
}

Affective symptoms, anxiety, neoplasms, palliative care, end of life 
What is already known about the topic?

- Death anxiety is common in patients with advanced cancer and may be targeted by intervention.

- Self-report measures of death anxiety are rarely used in clinical settings because their utility may not be evident.

\section{What this paper adds?}

- Self-reported death anxiety in patients with advanced cancer is affected by the awareness of and ability to reflect on mortality and may be used to identify individuals with differing levels of distress.

\section{Implications for practice, theory or policy}

- A self-report measure of death anxiety may facilitate exploration of this symptom as part of a clinical assessment and may help guide treatment approaches.

- Greater attention to death anxiety is consistent with and recommended by contemporary approaches to palliative care. 


\section{Introduction}

Humans face the existential challenge of knowing the inevitability of their personal demise. The fear and dread associated with anticipation of mortality is referred to as death anxiety $(1,2)$. This experience may broadly encompass concerns about the extinction of self and identity (1), the failure to have found personal meaning and social relatedness in life (3), the impact of death on loved ones (4), and the pain and suffering that may accompany the dying process (5). Death anxiety in response to the salience of mortality varies across individuals and over the life course (6) and has been related to differences in spirituality $(7,8)$, life stage $(4,9)$, attachment security $(10)$, self-worth (11), and coping strategies (12).

Research has tended to emphasize the universal experience of death anxiety and how it may motivate individuals to engage in culturally meaningful activity $(13,14)$. Self-report measures for this construct have been rarely used for clinical purposes and were often designed to be applicable to the general population whose fears may not be grounded in personal experience and exposure to actual death and dying (15-17). More recently, there has been renewed interest in measuring death anxiety in palliative populations because this symptom may be acute and especially debilitating in the context of impending mortality. Consequently, there is substantial clinical interest in the ability to intervene to improve this outcome (18).

Death anxiety has been found to be common in patients with advanced cancer (18) and its relief may be considered a primary goal of palliative care in this population (19). Death anxiety has been associated with negative outcomes, including impaired quality of life and psychiatric comorbidities such as depression and generalized anxiety $(20,21)$. Death anxiety is distressing to the family (20) and may hinder advance care planning and preparation for the end of life (22). A death anxiety scale tailored for use in patients with advanced cancer, the Death and Dying Distress Scale (DADDS) (23), has recently been validated and employed as an outcome in clinical trials (24). However, the interpretation and clinical utility of self-reported scores may not be evident without further linkage to the phenomenology of death anxiety as it emerges in clinical settings $(25,26)$.

The purpose of the present study was to inform our understanding of death anxiety in patients with advanced cancer by investigating the relationship between this selfreported symptom and its clinical presentation. This study may contribute to a better understanding of the construct of death anxiety within medical settings and suggest how its measurement may be incorporated into palliative care assessments to help guide treatment approaches.

\section{Method}

Setting/Context

Participants in this study were part of a clinical trial examining the efficacy of a brief psychotherapy intervention, Managing Cancer And Living Meaningfully (CALM) $(24,27)$ 
to alleviate distress in patients with advanced cancer. It was delivered by clinicians (i.e. psychiatrists and Master's level social workers) in the Department of Psychosocial Oncology and Palliative Care (now the Department of Supportive Care) at the Princess Margaret Cancer Centre, part of the University Health Network (UHN), in Toronto, Canada. Inclusion criteria for trial entry included adult age, English proficiency, and a confirmed diagnosis of advanced or metastatic cancer consistent with an expected prognosis of 12-18 months. Sixty-two psychotherapy participants were recruited between February 2012 and December 2012 while attending outpatient oncology clinic appointments and gave written informed consent. They were informed that therapy sessions would be audio-recorded and transcribed, and research reports would protect their anonymity. Study approval was obtained from the UHN Research Ethics Board (UHN REB \#09-0855-C).

Participants completed the 15-item Death and Dying Distress Scale (DADDS) (5) as part of a baseline assessment. The DADDS was developed for use in patients with advanced or metastatic cancer and assesses regret about lost time and opportunities, fears about the dying process, and concern about the impact of death on loved ones $(5,23)$. Each item is rated using the following values and anchors: $0=1$ was not distressed about this; $1=I$ experienced very little distress; $2=I$ experienced mild distress; $3=1$ experienced moderate distress; 4 = I experienced great distress; 5 = I experienced extreme distress. The scale generates a summed score ranging from 0 to 75, with higher scores indicating greater death-related distress.

\section{Sampling}

A stratified purposive sampling strategy was used to triangulate the quantitative measurement of death anxiety with its clinical presentation in the first session of therapy (28). Participants were selected to provide representation of groups with low, moderate, and high self-reported death anxiety at baseline. The strata were defined by cut-off values of 20 and 50, corresponding to the first and third quartiles in a prior psychometric study (23).

\section{Data Collection}

Nineteen audio-recorded first sessions were selected and transcribed verbatim. Of the 19 sessions, 3 were excluded from analysis due to incomplete recordings, resulting in a final sample of 16 participants with low $(n=6)$, moderate $(n=5)$, and high $(n=5)$ DADDS scores.

\section{Data Analysis}

Interpretive description was used to identify emergent themes and associations within the data $(29,30)$. This qualitative method involves inductive analysis to identify patterns and themes that may be useful to inform or develop clinical practice. The objective of this inductive framework is to attain a level of interpretation that provides insight about individual variability in clinical phenomena without striving for the development of new theory. A set of initial thematic categories was developed based on commonalities 
identified in the manifestations of death anxiety by the lead coder, ET, in consultation with $A D$ and $C L$. These categories were subsequently challenged, re-conceptualized and refined for greater clarity and parsimony of description based on discussions within the coding team. Coding discrepancies were resolved by achieving consensus between researchers. Techniques to enhance the rigour and trustworthiness of this process included negative case analysis and peer debriefing (31).

\section{Results}

\section{Sample Characteristics}

The 16 participants sampled for this study had a mean age of 57 years, $S D=10$, range $=$ 39 to 77 . Ten were female and six were male. Ten were married or in a common-law relationship, and the remainder were widowed $(n=4)$, separated or divorced $(n=1)$, or single $(n=1)$. The levels of education completed included post-graduate or professional school $(n=8)$, undergraduate university $(n=4)$, and college or trade school $(n=4)$. Fifteen participants self-identified as Caucasian and one as East or Southeast Asian. The disease site of the participants included: gynecological $(n=4)$, genitourinary $(n=4)$, gastrointestinal $(n=3)$, lung $(n=2)$, breast $(n=2)$, and sarcoma $(n=1)$. First therapy sessions occurred on average 20 days, $S D=15$, after completion of the baseline assessment.

\section{Findings}

Participant narratives about death and dying emerged during the collection of personal and family background, and discussions of distress and symptom onset in the first therapy session. The emergent themes in each stratum (i.e., low, moderate, high DADDS scores) are described and illustrated below with representative quotes (see Table 1 for an overview and description of the themes). Where relevant, participant talk is denoted by " $\mathrm{P}$ " and therapist talk by " $\mathrm{T}$ ".

Low DADDS Scores (0-19)

Non-reflectiveness about death was observed in participants who had not processed the threat of mortality. One participant who had been dealing with progressive metastatic cancer for two years discussed her future as follows:

The plan is I'm coming back to work as soon as I can. I'm getting done with chemo and curing myself as soon as I can and making this something of the past as soon as I can. They know I'm eventually coming back to work full-time.

(Participant \#1095)

These statements convey a sense of deliberate non-reflectiveness about the palliative nature of her condition and the possibility of death. This participant emphasized the importance of only "thinking positively" out of a belief that such an attitude would help to cure her cancer. The centrality of work in her life made it unthinkable that she should be unable to return to it. 
Other individuals described a more active process to avoid or suppress thoughts of mortality. As part of her normal functioning, this participant explained how she would evade or delay thinking about her disease and its meaning as much as possible:

P: Yeah, you know what with this whole thing that's happening to me, I think I tend to compartmentalize it all. I don't dwell on it. I don't think about it too much until you know, I have clinic today and then I have treatment at 3:30. So I really only start thinking about it, you know 15 minutes before I have to leave [...] I only thought about this on the elevator ride coming up here and trying to find the room.

T: In that short elevator or long elevator ride up, what were you wondering?

$P$ : Uhh you know what? Nothing really.

T: Nothing?

P: I was worried that I wouldn't have stuff to talk about.

(Participant \#1075)

This compartmentalization or avoidance allowed her to minimize contemplation of the future. She feared that thinking too much about the threat of mortality would trigger an unrecoverable depression, which would traumatize her young daughter. Her transcript conveyed an awareness of the threat of mortality and a turning away from it, as she was resistant to exploring this topic.

Readiness for death. In contrast, low self-reported death anxiety was also associated with an apparent psychological acceptance of death:

My illness is, as my mother would put it in her inimitable fashion, just one more cross to bear. I've prepared myself for the worst and all the details required. I spend my spring, summer and fall riding my bike through Cemetery $\mathrm{X}$, the last two years anyway, picking out my spot and what l'll have on top of it. I brought my daughter and my wife and my stepdaughter. My stepdaughter's going to turn 13 in June. I've had children in my life, my entire life, since I was 24.

(Participant \#1025)

The distinction between preparing versus succumbing to death resonated throughout this participant's session, as he was able to acknowledge the fact of death without fear of it. His acceptance was related to his resiliency, which he attributed to his personal growth in response to a punitive childhood, and to his sense of continuity and legacy in having contributed meaningfully to the next generation.

Moderate DADDS Scores (20-50)

Recognition of the inevitable. There was acknowledgement of prognosis and the noncurative intent of treatment in the moderate group. As one participant expressed: 
Just to come out at the end of it, I'm not going to be at a different place, there is no cure for me. You know at best, they say I could get maybe another three months.

(Participant \#1102)

This recognition of the imminence of death had a profound effect on this individual's decisions and plans for the future, motivating her to engage in frank discussions with her medical team and her family which might not have occurred otherwise. She sought to weigh the realistic costs and benefits of treatment with respect to quality of life at this late stage of disease:

$P:$ I think I'm leaning towards not doing it. It's kind of a scary decision.

$\mathrm{T}$ : Because of the finality of every decision you make?

P: Well exactly yeah, to not do it. And l've sort of canvassed my kids about it you know, and I don't want them to be angry with me, that I'm not doing it. It's not like I'm giving up, I don't feel that at all.

T: It sounds like you're choosing what you feel would be best for you and what you want.

P: Yeah, and controlling my destiny, and I go back to first principles. I've always said you know, as soon as I learn about all this, I do not want to, you know, poison myself just to die.

(Participant \#1102)

Given the palliative intent of treatment, she expressed a preference to forgo further chemotherapy in order to maximize the quality of time remaining with her loved ones.

Prior experience with death and its effect on coping. Prior experience with death was an emergent theme, relating to the ability to cope with the end of life. Individuals who had grieved and found peace following the death of a loved one expressed comfort in knowing that their families would also eventually find peace. This participant describes her thoughts about her family in light of her past experience with loss and letting go:

$P$ : The fact is, it's a big ugly elephant and it's in my room (chuckling) it's not in your room, it's not in the kids room, it's not in Name X's room, nobody else is going to die.

T: You don't think it's in their room?

$P$ : Not in the way it is in mine because I'm going to die. They're going to go on with their lives, thank God, they are going to have happy productive lives. That's what I want them to do, and they will. You know, I always say when my husband died, you know it's very painful to realize that life is for the living. He's gone, you go on living, and you can't help it you know. If you don't want to live, life is pushing you forward to live. So you know l've had, I've experienced loss.

(Participant \#1102) 
Conversely, exposure to a poor death could raise concerns about suffering:

I'm not interested in suffering and having a quality of life where I'm not independent and require care, and I would also like to be able to control my end [...] My worst fear is that I'm going to be like Name Y's husband who's in hospital, who can't do anything. He can't do for himself, so he can't, even if he wanted to, which I don't think he does, but he couldn't even end his life.

(Participant \#1118)

The image of her friend's husband served as an entry point into this participant's ruminations about the end of life, which included fears about helplessness and dependency, and allowed for discussion of what she considered to be good quality of life and of death.

High DADDS Scores (51-75)

Dominated by emotion. Participants in the high DADDS group reported feeling overwhelmed or consumed by a range of powerful emotions. These strong emotional responses appeared to hinder individual processing and preparation for the end-of-life. One individual, whose prostate cancer metastasized after he had discontinued active medical surveillance, described his anger and disappointment towards himself and his medical team:

T: Is part of you upset with yourself? Do you have-

P: Yeah I kill myself. I kill myself. It's all. I am sure they would have caught it sooner, or they would have seen something at some point [...] Well two things should have happened, the guy should have told me that my numbers were actually going up, so he didn't say anything. I never really knew that the numbers were actually rising and that I was pretty close to the number where they start doing tests. The second thing that should have happened is, the minute you don't come back for an appointment, they should call you. Doctor's offices don't do that. Dental offices will do that because it's money for them. Doctor offices don't have to worry. They're so busy, and if you miss an appointment, tough. Well that's crazy. How many lives would be saved if they just picked up the phone and called people to come back?

(Participant \#1035)

The unforeseen circumstances of his disease progression led this participant to remain preoccupied with feelings of blame and guilt, which made it difficult for him to further process, adapt to and prepare for the end of life.

A mother with young children elaborated upon her feelings of hopelessness:

I feel like a ticking bomb sometimes (shaky voice). Sometimes I feel like time is my friend, sometimes I feel like time is my enemy. I'm not quite sure (chuckling). 
You know, it's hard to stay positive. You know, when you feel good, it's easy to stay positive, but when you are not feeling so good or you got something kind of hanging over your head, it is hard to stay positive.

(Participant \#1111)

When the intrusiveness of illness into everyday functioning is minimal, it may be easier to remain hopeful that mortality has been delayed. Conversely, the experience of bodily decline can be demoralizing as an indicator of disease progression and the approach of death. This same participant continued to describe her sense of powerlessness at being unable to fight her disease:

I guess I'm a doer. I'm not somebody who sits by and, and that's how I feel. It's like, okay let's wait for something to happen and then we will react to it. And that's the kind of a doctor she is, that's kind of what we do, well no wonder everybody is dying [...] I'm not fighting cancer right now, I'm not fighting cancer (3 second pause) (sobbing) I'm just a sitting duck and nobody here cares.

(Participant \#1111)

Because so much of her hope had rested on being cured of disease, with the only remaining options of active monitoring and palliative care, she felt abandoned by her medical team.

Disappointment in intimate relationships was a source of considerable discussion. Some individuals were disappointed in themselves based on their perceived failure to support and care for loved ones who would be left vulnerable in the wake of their death, including young children and dependents. Others were disappointed in the supportiveness of close others. One participant was upset with her husband who was having difficulty accepting the severity of her disease. In this passage, she describes her feelings about his planning of a ski trip a year in advance:

T: You said you can't plan to travel, is it because you don't feel well?

P: Oh no, no I just don't want him to make plans for a one month ski trip next year. I don't know what my situation is going to be, I can be dead.

$\mathrm{T}$ : And he'll get mad at you if you're not there?

P: Well he gets angry that I'm not positive about it; he thinks I'm totally negative. And I'm trying to say, there's nothing positive about what I have, how can I be positive about it? You know, he's more like 'trying to live for the day' and that's fine and I can go with that, but then don't plan something a year down the road.

(Participant \#1136)

She was distressed by their lack of agreement about the meaning of advanced disease and how to cope with her impending death. She thought that the ski trip may have been an attempt by her husband to maintain a semblance of normality in their lives. 
Nonetheless, in so doing, she described feeling that her realistic concerns about the end of life were being dismissed.

Sense of unreality. Participants described feelings of confusion and disbelief at facing the end of life. This was sometimes heightened by the apparent disconnection between prognosis and one's current asymptomatic state:

$\mathrm{P}:$ I refuse to believe it.

$\mathrm{T}:[. .$.$] It's harder to believe that it's real, when you look and feel normal.$

P: I keep waiting for, I work out every day, 6 days a week let's say, but today I probably won't have a chance, um and I wear a heart rate monitor and um-

T: Why do you do that?

P: Because I want to see when I'm declining. I want to see when my cardiovascular fitness starts to decline.

(Participant \#1136)

The inability to make sense of the situation also involved feelings of unfairness about having progressive disease. This participant felt unjustly robbed of years of life that he had expected to enjoy:

I am mad about the fact that I am screwed out of 30 years. Both my parents lived 'til their, my dad died at 92. My mother had four cancers in her life and made it 'til 84. You know I'm going to be 54 in a month [...] Personally, I just can't believe that we're sitting here, in this position. I am feeling okay. I just can't believe I am sitting here and dealing with this shit.

(Participant \#1035)

\section{Discussion}

In patients with advanced cancer, self-reported death anxiety ratings may provide useful information about the psychological state of individuals and their reflective awareness of mortality. The dichotomous themes of readiness for death and non-reflectiveness about death were evident in individuals with low DADDS scores. Low self-reported death anxiety, it appears, may indicate a genuine acceptance of mortality from having resolved the issues that arise near the end of life, or may indicate the use of psychological avoidance as a coping strategy (assuming that individuals have been informed about their diagnosis). The latter is compatible with the notion that defensive reactions such as active suppression or denial of one's vulnerability may be selfprotective against cognitions and affect that are too threatening to acknowledge, such as those evoked by mortality $(12,32,33)$. For avoidant individuals, the experience of death anxiety may not be fully conscious or may remain unarticulated to self and others.

Individuals with moderate DADDS scores were found to be aware of impending mortality. Emergent themes highlighted this recognition, as this group struggled with treatment decisions and planning for the future. Consistent with the literature, prior 
experience with death may ease concerns about mortality (7), but also may sensitize individuals to the possibility of suffering (34). The themes evident among individuals with high DADDS scores concerned the overwhelming nature of their emotional experience and the difficulty of making sense of their situation. Their distress was exacerbated by worries about the impact of death on loved ones and the unavailability of emotional support in intimate relationships, aligning with previous research $(11,35$, 36).

There has been recognition that awareness of mortality and preparation for the end of life require clinical attention in advanced disease $(37,38)$. The ways in which clinical practice may change to address these issues is dependent on context and available resources. Supportive interventions for oncology teams have been developed to improve awareness and communication about end of life issues to alleviate distress and promote quality of life $(24,39-41)$. Their implementation may allow for earlier identification and treatment of patients having difficulty acknowledging and adapting to advanced disease. For individuals with persistent psychological issues, referral to specialized psychosocial care may be needed.

A measure of death anxiety tailored for patients with advanced cancer may be useful to clinicians to explore this symptom as part of routine clinical assessment. It offers a framework and probes to facilitate discussion about sources of death anxiety found to be relevant near the end of life. Self-report instruments should be understood as measuring the thoughts and feelings that individuals are willing to acknowledge (42). Individuals who respond with low death anxiety at clinical presentation may require special attention to determine their reflectiveness towards mortality and levels of psychological avoidance.

Psychosocial care may offer individuals an opportunity to explore and mitigate their fears about the future (43). Non-reflective individuals who engage in denial or avoidance may require gentle guidance toward a non-threatening discussion about death $(7,44)$. The readiness and urgency with which patients seek such discussion may depend on the trajectory and progression of disease. It is important to note that when individuals lack awareness of mortality or are defensively avoidant, then death anxiety may be expected to increase as their disease progresses and avoidance of its implications becomes less feasible. Individuals with moderate death anxiety may benefit from the reflective space afforded by psychosocial treatment to think through difficult decisions about the end of life, which include advance care planning and financial and caregiving arrangements (45). Patients with high death anxiety may benefit from the alleviation of acute distress before addressing underlying issues associated with death anxiety and preparation for end of life (46). The ability to experience a state of "double awareness" may be vital to psychological wellbeing in the context of advanced cancer (46). This state involves the capacity to balance fears of impending mortality against the possibilities that remain in life. It includes the idea that thinking about death and preparing for end of life are not identical to defeat or failure (47). 
There are limitations to the present study that may affect the transferability of its findings to other individuals and settings. Participants were English-speaking, mostly Caucasian, predominantly female, and relatively well-educated ambulatory patients attending a large urban cancer centre who were motivated to engage in a psychological intervention. The data were transcripts of first therapy sessions only and did not examine how death-related discussions may deepen or change over time with treatment. Themes were based on participant perspectives as articulated during the session and reflect the topics of discussion that developed. Therefore, the emergent themes cannot account for relevant aspects of experience that went unexplored (48).

\section{Conclusion}

Our findings indicate that self-reported death anxiety is affected by the awareness or ability to reflect on mortality. A self-report measure of death anxiety may facilitate exploration of this symptom as part of a clinical assessment and may serve to guide treatment approaches. Greater attention to death anxiety and the adaptive challenges facing individuals under threat of mortality is consistent with and recommended by contemporary approaches to palliative care.

Funding: This study was funded by a research grant from the Canadian Institutes of Health Research (CIHR \#MOP 106473). This research was also supported in part by The Princess Margaret Cancer Foundation (PMCF) Hertz Centre Fund, The PMCF Kirsh Family Fund, and by the Ontario Ministry of Health and Long Term Care (OMOHLTC). The views expressed do not necessarily reflect those of the OMOHLTC. Dr. Rodin is also supported by the University of Toronto/University Health Network Harold and Shirley Lederman Chair in Psychosocial Oncology and Palliative Care. The funders had no role in the final design, analysis and writing of this study.

Conflict of Interest: None declared.

Acknowledgements: We would like to thank the participants for their time and effort to complete this study. We also thank our research staff and our CALM therapists, Valerie Heller, Cheryl Kanter, Rhonda Kibrick-Lazear, and Jenny Shaheed for their valuable contributions to this study. 
Table 1. Overview of death anxiety themes.

\begin{tabular}{|c|c|c|}
\hline DADDS Score & Theme & Definition \\
\hline \multirow{2}{*}{$\begin{array}{l}\text { Low } \\
(0-19)\end{array}$} & 1. Non-reflectiveness about death & Absence of awareness or inability to think about mortality \\
\hline & 2. Readiness for death & Preparation and acceptance of end of life \\
\hline \multirow{2}{*}{$\begin{array}{l}\text { Moderate } \\
(20-50)\end{array}$} & 1. Recognition of the inevitable & Acknowledgement of impending mortality \\
\hline & $\begin{array}{l}\text { 2. Prior experience with death and its } \\
\text { effect on coping }\end{array}$ & $\begin{array}{l}\text { Impact of past death-related events on resilience or vulnerability to the } \\
\text { threat of mortality }\end{array}$ \\
\hline \multirow{3}{*}{$\begin{array}{l}\text { High } \\
(51-75)\end{array}$} & 1. Dominated by emotion & Experience of being overwhelmed or consumed by powerful feelings \\
\hline & $\begin{array}{l}\text { 2. Disappointment in intimate } \\
\text { relationships }\end{array}$ & $\begin{array}{l}\text { Dissatisfaction with self or others in the fulfillment of social } \\
\text { responsibilities and obligations }\end{array}$ \\
\hline & 3. Sense of unreality & Inability to make sense of living with advanced disease \\
\hline
\end{tabular}




\section{References}

1. Lehto RH, Stein KF. Death anxiety: An analysis of an evolving concept. Res Theory Nurs Pract 2009; 23: 23-41.

2. Wong PTP, Reker GT, Gesser G. The Death Attitude Profile-Revised (DAP-R): A multidimensional measure of attitudes towards death. In: Neimeyer RA (ed) Death Anxiety Handbook: Research, Instrumentation, and Application. Washington: Taylor \& Francis, 1994, pp.121-148.

3. Erikson EH. The life cycle completed. Extended version with new chapters on the ninth stage by Joan M. Erikson. New York: WW Norton and Company, 1998.

4. Adelbratt S, Strang P. Death anxiety in brain tumour patients and their spouses. Palliat Med 2000; 14: 499-507.

5. Lo C, Hales S, Zimmermann C, Gagliese L, Rydall A, Rodin G. Measuring deathrelated anxiety in advanced cancer: Preliminary psychometrics of the Death and Dying Distress Scale. J Pediatr Hematol Oncol 2011; 33: S140-S145.

6. Cicirelli VG. Personal meanings of death in older adults and young adults in relation to their fears of death. Death Stud 2001; 25: 663-683.

7. Gibbs HW, Achterberg-Lawlis J. Spiritual values and death anxiety: Implications for counseling with terminal cancer patients. J Couns Psychol 1978; 25: 563-569.

8. Florian V, Kravetz S. Fear of personal death: Attribution, structure, and relation to religious belief. J Pers Soc Psychol 1983; 44: 600-607.

9. Rasmussen CA, Brems C. The relationship of death anxiety with age and psychosocial maturity. J Psychol 1996; 130: 141-144.

10. Sand $L$, Olsson $M$, Strang P. Coping strategies in the presence of one's own impending death from cancer. J Pain Symptom Manage 2009; 37: 13-22.

11. Neel C, Lo C, Rydall A, Hales S, Rodin G. Determinants of death anxiety in patients with advanced cancer. BMJ Support Palliat Care 2015; 5: 373-380.

12. Vos MS, De Haes JCJM. Denial in cancer patients, an explorative review. Psychooncology 2007; 16: 12-25.

13. Becker E. The Denial of Death. New York: Free Press, 1973.

14. Greenberg J, Solomon S, Pyszczynski T. Terror management theory of selfesteem and cultural worldviews: Empirical assessments and conceptual refinements. In: Mark P (ed) Advances in Experimental Social Psychology. San Diego: Academic Press, 1997; pp. 61-139.

15. Conte HR, Weiner MB. Measuring death anxiety: Conceptual, psychometric, and factor-analytic aspects. Pers Soc Psychol Rev 1982; 43: 775-785.

16. Dickstein LS. Death concern: Measurement and correlates. Psychol Rep 1972; 30: 563-571.

17. Templer DI. The construction and validation of a death anxiety scale. J Gen Psychol 1970; 82: 165-177.

18. Royal KD, Fereshte E. Psychometric properties of the Death Anxiety Scale (DAS) among terminally ill cancer patients. J Psychosoc Oncol 2011; 29: 359-371.

19. Zimmermann $C$, Wennberg R. Integrating palliative care: a postmodern perspective. Am J Hosp Palliat Care 2006; 23: 255-258. 
20. Sherman DW, Norman R, McSherry CB. A comparison of death anxiety and quality of life of patients with advanced cancer or AIDS and their family caregivers. J Assoc Nurses AIDS Care 2010; 21: 99-112.

21. Gonen G, Kaymak SU, Cankurtaran ES, Karslioglu EH, Ozalp E, Soygur H. The factors contributing to death anxiety in cancer patients. J Psychosoc Oncol 2012; 30: 347-358.

22. Brown AJ, Shen MJ, Ramondetta LM, Bodurka DC, Giuntoli RL, Diaz-Montes T. Does death anxiety affect end-of-life care discussions? Int J Gynecol Cancer 2014; 24: 1521-1526.

23. Krause S, Rydall A, Hales S, Rodin G, Lo C. Initial validation of the Death and Dying Distress Scale for the assessment of death anxiety in patients with advanced cancer. J Pain Symptom Manage 2015; 49: 126-134.

24. Lo C, Hales S, Jung J, Chiu A, Panday T, Rydall A, et al. Managing Cancer And Living Meaningfully (CALM): phase 2 trial of a brief individual psychotherapy for patients with advanced cancer. Palliat Med 2014; 28: 234-242.

25. Beshai JA, Naboulsi MA. Existential perspectives on death anxiety. Psychol Rep 2004; 95: 507-513.

26. Teddlie C, Yu F. Mixed Methods Sampling: A Typology With Examples. J Mix Methods Res 2007; 1: 77-100.

27. Nissim R, Freeman E, Lo C, Zimmermann C, Gagliese L, Rydall A, et al. Managing Cancer and Living Meaningfully (CALM): a qualitative study of a brief individual psychotherapy for individuals with advanced cancer. Palliat Med 2012; 26: 713721.

28. Tashakkori A, Teddlie C. Handbook of Mixed Methods in Social \& Behavioral Research. Thousand Oaks: Sage Publications, 2003.

29. Thorne S, Kirkham SR, MacDonald-Emes J. Focus on qualitative methods. Interpretive description: a noncategorical qualitative alternative for developing nursing knowledge. Res Nurs Health 1997; 20: 169-177.

30. Thorne S, Kirkham SR, O'Flynn-Magee K. The analytic challenge in interpretive description. Int J Qual Methods 2004; 3: 1-11.

31. Lincoln YS, Guba EG. Naturalistic Inquiry. Newbury Park: Sage Publications, 1985.

32. Pyszczynski T, Greenberg J, Solomon S. A dual-process model of defense against conscious and unconscious death-related thoughts: An extension of terror management theory. Psychol Rev 1999; 106: 835-845.

33. Rabinowitz T, Peirson R. "Nothing is wrong, doctor": Understanding and managing denial in patients with cancer. Cancer Invest 2006; 24: 68-76.

34. Maddi SR. Developmental value of fear of death. J Mind Behav 1980; 1: 85-92.

35. Lo C, Hales S, Braun M, Rydall AC, Zimmermann C, Rodin G. Couples facing advanced cancer: examination of an interdependent relational system. Psychooncology 2013; 22: 2283-2290.

36. Grumann MM, Spiegel D. Living in the face of death: Interviews with 12 terminally ill women on home hospice care. Palliat Support Care 2003; 1: 23-32.

37. Clayton JM, Hancock KM, Butow PN, Tattersall MH, Currow DC. Clinical practice guidelines for communicating prognosis and end-of-life issues with adults in the 
advanced stages of a life-limiting illness, and their caregivers. Med J Aust 2007; 186: S77-S79.

38. Pfeil TA, Laryionava K, Reiter-Theil S, Hiddemann W, Winkler EC. What keeps oncologists from addressing palliative care early on with incurable cancer patients? An active stance seems key. Oncologist 2015; 20: 56-61.

39. Baile WF, Buckman R, Lenzi R, Glober G, Beale EA, Kudelka AP. SPIKES-A six-step protocol for delivering bad news: Application to the patient with cancer. Oncologist 2000; 5: 302-311.

40. Bakitas M, Lyons KD, Hegel MT, Balan S, Brokaw FC, Seville J, et al. Effects of a palliative care intervention on clinical outcomes in patients with advanced cancer: the Project ENABLE II randomized controlled trial. JAMA 2009; 302: 741749.

41. Hannon B, Swami N, Pope A, Rodin G, Dougherty E, Mak E, et al. The oncology palliative care clinic at the Princess Margaret Cancer Centre: An early intervention model for patients with advanced cancer. Support Care Cancer 2014; 23: 1073-1080.

42. Moyer A, Levine EG. Clarification of the conceptualization and measurement of denial in psychosocial oncology research. Ann Behav Med 1998; 20: 149-160.

43. Rodin G, Zimmermann C. Psychoanalytic reflections on mortality: A reconsideration. J Am Acad Psychoanal Dyn Psychiatry 2008; 36: 181-196.

44. Zimmermann C. Death denial: obstacle or instrument for palliative care? An analysis of clinical literature. Sociol Health IIIn 2007; 29: 297-314.

45. Hales S, Zimmermann C, Rodin G. The quality of dying and death. Arch Intern Med 2008; 168: 912-918.

46. Rodin G, Lo C, Mikulincer M, Donner A, Gagliese L, Zimmermann C. Pathways to distress: the multiple determinants of depression, hopelessness, and the desire for hastened death in metastatic cancer patients. Soc Sci Med 2009; 68: 562-569.

47. Spiegel D. Psychotherapeutic intervention with the medically ill. In: Janowsky DS (ed) Psychotherapy Indications and Outcomes. Washington: American Psychiatric Press, Inc., 1999.

48. Maxwell JA. Understanding and validity in qualitative research. Harvard Educ Rev 1992; 62: 279-301. 